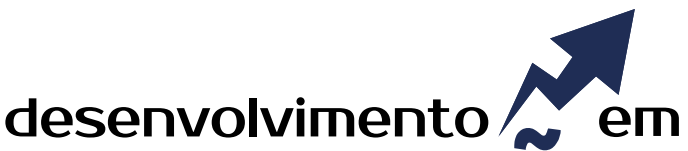 QUESTÃO
}

\section{Processos Participativos na Gestão de Universidades Federais: \\ o caso da Universidade Federal da Fronteira Sul}

http://dx.doi.org/10.21527/2237-6453.2018.45.233-248

Recebido em: 2/9/2016

Aceito em: 31/1/2018

\section{Fernanda Mara Peretti ${ }^{1}$, Márcia Luíza Pit Dal Magro², Irme Salete Bonamigo ${ }^{3}$, Dunia Comerlatto ${ }^{4}$}

\begin{abstract}
RESUMO
As mobilizações reivindicatórias que ocorreram no Brasil, a partir de 1980, foram fundamentais para a construção de uma gestão político-administrativa mais participativa em diferentes organizações públicas, incluindo as universidades federais. A expansão do Ensino Superior público, desde os anos 2000, possibilitou a criação de novas universidades, como a Universidade Federal da Fronteira Sul (UFFS). Este artigo discute a gestão universitária ante as mudanças na administração pública, com o objetivo de analisar os processos participativos inerentes à criação e gestão da UFFS. O estudo, de cunho qualitativo, utilizou como técnicas de pesquisa entrevistas semiestruturadas, observação participante e pesquisa documental. 0 processo participativo da comunidade local/regional na interação com os movimentos sociais, diferenciou o processo de constituição e estruturação da UFFS. Quatro Conselhos Gestores compõem sua estrutura, na perspectiva de favorecer e ampliar processos participativos de gestão universitária. O Conselho Estratégico Social se constitui em potência macrorregional para a construção de uma universidade comprometida com a participação popular, a inclusão social e o desenvolvimento regional. "Fazer a gestão da UFFS", em estreito diálogo com as comunidades interna e externa, por meio de seus Conselhos Gestores, a fim de promover e efetivar uma cultura política de participação, contudo, ainda se constitui um desafio em seus processos de gestão universitária.
\end{abstract}

Palavras-chave: Administração pública. Gestão universitária. Participação.

PARTICIPATORY PROCESSES IN THE FEDERAL UNIVERSITIES MANAGEMENT: THE CASE OF THE FRONTEIRA SUL UNIVERSITIES

\begin{abstract}
The claim mobilizations that occurred in Brazil since 1980, were crucial to organize a more participative political-administrative management in different public organizations, including federal universities. The expansion of public higher education, since the 2000s, it was enabled to create new universities, such as Universidade Federal da Fronteira Sul (UFFS). This article discusses the university management in light of changes occurred in the public administration and refers to an analysis of participatory processes involved the creation and management of the UFFS. The study, of qualitative nature, used semi-structured interviews, participant observation and documentary research as research technics. The community participatory process of local/regional in interaction with social movements that differentiate the process of creation and organization of the UFFS. Four Councils managers composing its structure with a perspective to promote and expand participatory processes of university management. The Strategic Social Council is constituted in a macro-regional power for the construction of a university committed to popular participation, social inclusion and regional development. However, "to manage the UFFS" in strait dialogue with the internal and external communities through their management councils, to promote the overcoming of the political culture of participation that it show yet fragile in its management university processes.
\end{abstract}

Keywords: Public administration. University Management. Participation.

\footnotetext{
${ }^{1}$ Mestre em Políticas Sociais e Dinâmicas Regionais pela Universidade Comunitária Regional de Chapecó. Técnica da Universidade Federal da Fronteira Sul. fernanda.peretti@hotmail.com

${ }^{2}$ Doutora em Psicologia pela Universidade Federal de Santa Catarina. Professora do Programa de Pós-Graduação em Políticas Sociais e Dinâmicas Regionais da Universidade Comunitária Regional de Chapecó. mapit@unochapeco.edu.br

${ }^{3}$ Doutora em Psicologia Social pela Universidade Estadual do Rio de Janeiro. Professora do Programa de Pós-Graduação em Políticas Sociais e Dinâmicas Regionais da Universidade Comunitária Regional de Chapecó. bonamigo@unochapeco.edu.br

${ }^{4}$ Doutora em Serviço Social pela Pontifícia Universidade Católica do Rio Grande do Sul. Professora do Programa de Pós-Graduação em Políticas Sociais e Dinâmicas Regionais da Universidade Comunitária Regional de Chapecó. dunia@unochapeco.edu.br
} 
$\mathrm{O}$ atual modelo de gestão das universidades federais brasileiras se constituiu em sintonia com as mudanças que ocorreram na administração pública do país. Nesse sentido, as mobilizações reivindicatórias que aconteceram a partir da década de 80 e que se inscrevem no que De Paula (2005) denomina de modelo societal, foram fundamentais para a construção de um gerenciamento mais participativo, em que se destacam os processos de eleição e as estruturas colegiadas de gestão nas universidades públicas. Desde a década de 90, no entanto, a adoção do modelo gerencial vem impondo novos instrumentos e práticas de gestão, os quais, de acordo com Ribeiro (2013), ameaçam os processos participativos nessas instituições.

Essas mudanças ocorrem em um cenário de expansão do Ensino Superior público, o qual é possível por meio da criação do Programa de Apoio aos Planos de Reestruturação e Expansão das Universidades Federais (Reuni), lançado pelo governo federal por meio do Decreto n. 6.096 de 24 de abril de 2007. Mediante esse Programa foram previstas várias ações, que vão desde o combate à evasão até a ampliação da oferta de vagas e a criação de novas Instituições de Ensino Superior (IES).

É nesse contexto que se cria a Universidade Federal da Fronteira Sul (UFFS), uma Instituição de Ensino Superior pública e popular, criada pela Lei n. 12.029, de 15 de setembro de 2009. A UFFS abrange os 396 municípios da Mesorregião Fronteira Mercosul - Sudoeste do Paraná, Oeste de Santa Catarina e Noroeste do Rio Grande do Sul (UNIVERSIDADE..., 2012a), região em que o Estado brasileiro esteve historicamente ausente no que diz respeito à oferta de Ensino Superior.

Desde sua instalação, a UFFS conta com cinco campi: Chapecó (SC), onde fica localizada a Reitoria e o Campus Chapecó, Campus Realeza (PR), Campus Laranjeiras do Sul (PR), Campus Cerro Largo (RS) e Campus Erechim (RS). Em 2013 cria-se o Campus Passo Fundo (RS), destinado à oferta do curso de medicina. Em tempos atuais, agrega um número aproximado de 1.000 servidores públicos federais e 8.000 alunos, regularmente matriculados nos cursos de Graduação e Pós-Graduação.

Este artigo discute a gestão universitária ante as mudanças na administração pública, com o objetivo de analisar os processos participativos inerentes à criação e gestão da UFFS. Trata-se de uma universidade pública recentemente estabelecida no Brasil, que se difere, em sua constituição e estrutura de gestão, de outras universidades no âmbito federal, o que atribui importância em estudá-la.

O tema participação na gestão de universidades públicas é objeto de diferentes pesquisas. Como discute Carvalho (2013, p. 351), os estudos podem ser categorizados em dois grandes grupos. Um que aborda o tema "[...] como uma dimensão técnica de engajamento limitada à função que cada segmento da comunidade universitária exerce". Outro que aborda a participação como uma necessidade inerente à ampliação dos processos democráticos, defendendo que seja menos desigual entre os diferentes segmentos. Na perspectiva deste segundo grupo, pontuam-se, a seguir, reflexões sobre a gestão da administração pública no Brasil e as mudanças ocorridas, bem como a participação como fundamento dos processos de gestão universitária, na particularidade da Universidade Federal da Fronteira Sul. 


\section{MÉTODO DO ESTUDO}

O estudo realizado na Universidade supracitada, caracteriza-se de abordagem qualitativa, foi realizado no período de agosto de 2013 a abril de 2014, seguindo os protocolos éticos previstos pela Resolução n. 466/CNS/2012. O levantamento e análise das informações produzidas foram realizados utilizando princípios e conceitos da pesquisa social proposta por Minayo (2008). Em um primeiro momento, detalhou-se o campo das determinações fundamentais, mapeado na fase exploratória da investigação para, em um segundo momento, considerado interpretativo, articular com as informações oriundas do campo, o sentido, a lógica interna, as projeções e interpretações (MINAYO, 2008).

Conforme sugerido por Minayo (2008), em todo o processo de produção do conhecimento buscou-se identificar: (a) história e origem da universidade e do grupo que a compõe, de seus ambientes, de suas condições socioeconômicas e políticas, da participação dos diferentes atores que compõem a estrutura da universidade, como alunos, técnicos, professores e comunidade em geral e a forma como ocorre a inserção desses atores na estrutura comum da universidade e o seu nível de participação nos processos decisórios; (b) configurações da estrutura organizacional da universidade, o fluxo dos processos decisórios e a relação com os participantes; (c) o reconhecimento da estrutura por parte dos sujeitos entrevistados, suas perspectivas e expectativas, bem como suas visões anteriores à UFFS, relacionando com a forma em que as demais instituições de ensino se organizam e seu reflexo na expectativa que se tem do papel desta universidade; (d) identificação dos indícios que relacionam a forma de gestão da universidade às teorias da administração pública.

Para o levantamento das informações relacionadas, utilizou-se como técnicas de pesquisa entrevistas, observações com registro em diário de campo e pesquisa documental. A pesquisa documental abrangeu documentos como Estatuto, Regimento, atas de reuniões, portarias, legislação vigente, entre outros. Nesta etapa buscou-se, nos documentos, também a identificação dos atores envolvidos em fluxos decisórios institucionais, relacionados à criação e funcionamento dos restaurantes universitários, estabelecimento do curso de Medicina - Campus Passo Fundo - e criação das normas protocolares das solenidades de colação de grau. Assim, as entrevistas foram realizadas com sete sujeitos que participaram de fluxos decisórios na universidade: cinco docentes (dois deles membros do corpo diretivo da UFFS), um técnico-administrativo e um membro dos movimentos sociais. As observações participantes ocorreram por meio do acompanhamento pela pesquisadora dos processos decisórios supramencionados, e foram registradas em diário de campo.

As informações decorrentes das entrevistas complementaram as levantadas nas observações e pesquisa documental e foram analisadas por meio da análise temática proposta por Minayo (2008), ou seja, foi considerada a presença qualitativa dos temas investigados e emergentes que denotam valores e atitudes presentes nos discursos. 0 processo de análise temática, com base na autora, abrangeu três etapas: (a) pré-análise: seleção dos documentos e articulação com os objetivos da pesquisa; leitura flutuante de todo o material de pesquisa; e constituição do corpus de modo a contemplar todos os aspectos levantados, com representação do universo de pesquisa, com contempla- 
ção dos critérios estabelecidos e adequados aos objetivos da pesquisa; (b) exploração do material, buscando o núcleo de compreensão e a especificação dos temas; (c) interpretação com base na fundamentação teórica e outras dimensões sugeridas pela leitura do material.

\section{MUDANÇAS NA ADMINISTRAÇÃO PÚBLICA E SEUS REFLEXOS NA GESTÃO UNIVERSITÁRIA}

A gestão da administração pública no Brasil passou por significativas mudanças ao longo da História, as quais são importantes a fim de compreender o atual contexto de gestão das universidades federais do país e dos processos participativos no seu interior. Pode-se destacar quatro modelos principais presentes na administração pública brasileira: (1) patrimonialista; (2) burocrático; (3) gerencialista; (4) societal.

O primeiro modelo que orientou a administração pública brasileira, de acordo com Costa (2008), abrange desde o Período Colonial até a Revolução de 1930. De Paula (2003) observa que, nesse contexto, o Estado se caracterizava como uma unidade política centrada na figura do rei e seus conselheiros. Isso contribuiu para que houvesse uma centralização do poder na cúpula e o autoritarismo do poder público, características que se tornaram traços distintivos da administração pública brasileira e constituíram o que a autora chama de tradição patrimonialista. Entre as heranças desse modelo, De Paula (2003) destaca:

[...] os empregos e benefícios que se auferem do Estado costumam estar ligados a interesses pessoais e não aos interesses públicos objetivos. Este personalismo do serviço público brasileiro relaciona-se com a ética de fundo emotivo que permeia nossa cultura: o "homem cordial" é avesso à impessoalidade e ao formalismo e, consequentemente, à burocracia (p. 107).

De acordo com Costa (2008, p. 869), o primeiro governo Vargas representa um marco na administração pública do país, tendo em vista que "[...] realizou o primeiro esforço deliberado, sistemático e continuado de modernização administrativa", introduzindo o modelo da Administração Burocrática. Secchi (2009, p. 351) afirma que no modelo burocrático, "o poder emana das normas, das instituições formais e não do perfil carismático ou da tradição". O autor ainda complementa que desse modelo "derivam três características principais: a formalidade, a impessoalidade e o profissionalismo".

A formalidade está baseada na criação de rotinas padronizadas e documentadas, respeitando uma hierarquia administrativa que não permite a discricionariedade das pessoas perante os processos. A impessoalidade está fundamentada no fato de que as posições de chefia nas organizações não pertencem a quem as ocupa, uma vez que essa situação pode ser temporária, mas pertencem à organização da instituição. Já o profissionalismo visa à promoção das pessoas a cargos e/ou funções de acordo com sua capacidade e mérito, excluindo-se hipóteses de nepotismo (SECCHI, 2009).

Um terceiro momento da Administração Pública brasileira se dá com a inserção da chamada Nova Administração Pública ou Gerencialismo, que emergiu no Brasil na década de 90 a partir de iniciativas do ex-ministro Luiz Carlos Bresser-Pereira, ao assumir a direção do então Ministério da Administração e Reforma do Estado (Mare). A profissionalização e o uso de práticas de gestão, transpostas do setor privado para o setor 
público, constituiu-se no seu principal objetivo. Sobre isso, Prado (2011, p. 264) destaca que "a emergência do gerencialismo se deveu à crise de credibilidade que a administração pública atravessava em vários países, abrindo espaço para uma demanda crescente por práticas da administração empresarial". Na Administração Pública Gerencial o Estado passa a ser visto como um prestador de serviços ao cidadão e, para isso, utiliza instrumentos de mercado para garantir a eficiência e a eficácia de suas organizações. Para Ésther (2011, p. 651), o modelo gerencial implica responsabilidade das decisões ao gestor público, que, dotado "de uma racionalidade gerencial, poderia dar conta de resolver todos os problemas que lhe são colocados". Esta capacidade, segundo a autora, seria decorrente de um treinamento que lhe possibilitaria "isolar as atividades umas das outras e aquelas da autoridade direta e para avaliar o desempenho dos serviços e das atividades governamentais por meio de indicadores objetivos". Na gestão das universidades públicas, no entanto, de acordo com Ribeiro (2013), a restrição dos processos participativos e a decorrente centralização do poder são efeitos dessa transposição da lógica empresarial para o setor educacional.

Em contraposição a esses modelos, surgem outras vertentes que defendem uma gestão pública focada na participação e na democracia de modo a reforçar a autonomia de instituições sociais, como é o caso das universidades federais. De Paula (2005) afirma que, a partir da década de 80 , por meio de inúmeras mobilizações reivindicatórias em que se destaca a atuação de diversos movimentos sociais, emerge um novo modelo de Administração Pública no Brasil, conhecido como societal, que se refere à

[...] implementação de um projeto político que procura ampliar a participação dos atores sociais na definição da agenda política, criando instrumentos para possibilitar um maior controle social sobre as ações estatais, desmonopolizando a formulação e a implementação das ações públicas (p. 4).

Nessa lógica, "a administração pública é entendida como sendo uma ação político-deliberativa, na qual o indivíduo participa decidindo seu destino como cidadão, eleitor, trabalhador ou consumidor" (DE PAULA, 2005, p. 45). A Administração Societal vem ao encontro da perspectiva da gestão social desenvolvida por Tenório (1998, p. 16), contrapondo-se "[...] à gestão estratégica na medida em que tenta substituir a gestão tecnoburocrática, monológica, por um gerenciamento mais participativo, dialógico, no qual o processo decisório é exercido por meio de diferentes sujeitos sociais".

A sociedade organizada constitui-se como fator fundamental e participante dos processos decisórios e da formulação de políticas públicas. No que diz respeito às heranças que este último modelo deixou às universidades públicas, destaca-se os processos eleitorais e as estruturas colegiadas de gestão, que, de acordo com Ribeiro (2013), ainda se apresentam como possibilidade real de participação da comunidade acadêmica, com potencial de transformação política.

\section{PROCESSOS PARTICIPATIVOS NA CONSTITUIÇÃO E ESTRUTURAÇÃO DA UFFS}

As regiões Oeste de Santa Catarina, Sudoeste do Paraná e Noroeste do Rio Grande do Sul apresentam características econômicas e culturais semelhantes, bem como dificuldades e desafios comuns, o que, de acordo com Renk (2006), têm origem ainda no 
processo de colonização desse "grande território". Nesse contexto, foram desenvolvidas ações com vistas ao desenvolvimento regional, como é o caso do Plano de Desenvolvimento Sustentável da área da Bacia do Rio Uruguai de 1997, instituído pelo Ministério do Planejamento e Orçamento e Gestão (MPOG).

A partir da necessidade de dinamizar essa grande região, distribuindo de uma forma mais consistente e equitativa as atividades produtivas, nasce o conceito de Mesorregião da Grande Fronteira do Mercosul, dada a criação de um Fórum que abrange desde o Norte e Noroeste do Rio Grande do Sul, Oeste de Santa Catarina até o Sudoeste do Paraná. Assim, em 28 de novembro de 2002 cria-se, oficialmente, o Fórum de Desenvolvimento da Mesorregião da Fronteira Sul, o qual se constitui como sociedade civil de direito privado, sem fins lucrativos e com duração indeterminada. De acordo com seu Estatuto, tem como finalidade articular e estimular a ação conjunta das entidades públicas, privadas e da sociedade civil, representativas dos diferentes segmentos da sociedade mesorregional. Ainda, busca promover estudos, opinar sobre políticas e formular propostas destinadas ao desenvolvimento integrado e sustentável e à redução das disparidades inter e intrarregionais no âmbito dessa Mesorregião (FÓRUM..., 2002).

Com essa organização da sociedade civil, nasce uma demanda pelo Ensino Superior público para a região da Grande Fronteira com o Mercosul, a partir da luta de diferentes organizações da sociedade civil na busca de suprir a demanda de uma região em que o Ensino Superior, de caráter público federal, não estava presente. Esse processo contou com a participação e representação de diversas Organizações Não Governamentais, Igrejas e Movimentos Sociais, resultando na criação, em 2005, do Movimento Pró-Universidade Federal. Sobre isso, Benincá (2011, p. 41-42) ressalta que,

Com a participação de movimentos sociais, setores da Igreja Católica, lideranças políticas, governamentais, sindicais e empresariais, representantes de entidades e de instituições de ensino, o "mutirão" regional pela universidade federal e popular ganhava corpo. $O$ projeto se fortaleceu com a junção de forças do movimento que lutavam com o mesmo objetivo no Oeste de Santa Catarina e no Sudoeste do Paraná, regiões estas com realidades sociais, culturais e econômicas muito comuns.

Um dos sujeitos que participou da instituição da UFFS relembra, em sua entrevista, sobre a participação dos Movimentos Sociais:

Nós tínhamos vários movimentos participando da discussão: Movimentos dos Sem Terra, das Mulheres Camponesas, a Fetraf, a CUT, Movimento Sindical, que têm objetos de luta diferentes e que, portanto, têm divergências, evidentemente; mas esses movimentos colocaram as divergências em segundo plano e se colocaram na perspectiva do objetivo comum que era a luta por uma universidade federal na região (SUJEITO X1).

Ainda, relembra a forma como se deu essa participação, destacando que a população mobilizada integrava as reuniões organizadas pela comissão e se manifestava com relação ao que se esperava da universidade a ser instalada na mesorregião:

A forte manifestação dos movimentos sociais, de pessoas que não têm o Ensino Médio, que talvez não tenham terminado o Ensino Fundamental e que estavam lá enchendo a sala cada vez que a gente fazia seminários, com a capacidade de dizer com tanta clareza qual é a universidade que queriam pra região, pros filhos delas, pros filhos que não são filhos dela (SUJEITO X1). 
Após a nomeação da Comissão de Implantação da Universidade Federal da Fronteira Sul, iniciaram-se os trabalhos de maneira intensificada para tal. Com base no que relatou o sujeito $\mathrm{X} 1$, esse processo participativo da comunidade local/regional e dos movimentos sociais diferenciou o processo de constituição e gestão da UFFS desde o início. Um aspecto dessa diferenciação pode ser destacado pela oferta de cursos de Graduação que privilegiam as vocações da economia regional, com vistas ao desenvolvimento regional integrado (UNIVERSIDADE..., 2012a). Outro aspecto foi o processo de ingresso dos alunos, discutido pela comissão, que, em conjunto com os movimentos sociais, criou o fator escola pública, ou seja, a partir da nota do Exame Nacional do Ensino Médio (Enem), quando o candidato ganharia uma aceleração na pontuação de acordo com o tempo que permaneceu no ensino público (UNIVERSIDADE..., 2011).

Para o sujeito $\mathrm{X} 1$ este último aspecto permitiu que alunos oriundos do ensino público tivessem uma chance maior de ingresso na universidade, assegurando o atendimento a uma população menos favorecida economicamente:

Como é que nós chegamos à forma, por exemplo, do Enem? O Enem como o caminho para se chegar à universidade, mas nós temos que atingir os nossos estudantes aqui da região, os estudantes pobres da região que não conseguiram sair pra estudar. 0 produto dessas conversas foi um momento de muito aprendizado, de ouvir a comunidade mesmo e a universidade ir se organizando e ir encontrando na sua estrutura, no seu jeito de ser universidade, encontrando brechas de fazer diferente mesmo. Fazer uma universidade com uma cara diferente. Eu acho que essa questão do fator escola pública foi um exemplo importantíssimo (SUJEITO X1).

Nessa direção, em 2012 a UFFS adotou as diretrizes do governo federal no que diz respeito à oferta de vagas respeitando as cotas e, posteriormente, ao ingresso de alunos via Sistema de Seleção Unificada do Governo Federal (Sisu). Ainda, a contribuição do Programa de Apoio a Planos de Reestruturação e Expansão das Universidades Federais (Reuni) foi fundamental para que, no conjunto das forças sociais mobilizadas nessa messorregião, a UFFS fosse viabilizada.

Ao considerar que processos participativos, envolvendo comunidades e movimentos sociais, caracterizaram fortemente a constituição e estruturação da UFFS, discute-se, a seguir, essa participação como fundamento de sua gestão universitária.

\section{A Participação na Gestão Universitária da UFFS}

A Lei 9.394, de 20 de dezembro de 1996, estabelece as Diretrizes e Bases da Educação Nacional (LDB) e, em seu Capítulo IV, dispõe sobre a Educação Superior e descreve sobre as finalidades e obrigatoriedades na atuação das universidades públicas federais. Destaca-se que a participação dos sujeitos na composição dos órgãos deliberativos e a forma de estruturação dos Conselhos nessas universidades também estão previstas. 0 artigo 56 da Lei supracitada estabelece que "as instituições públicas de educação superior obedecerão ao princípio da gestão democrática, assegurada a existência de órgãos colegiados deliberativos, de que participarão os segmentos da comunidade institucional, local e regional". 
Assim, apesar do ideário produtivista e mercadológico oriundo do modelo gerencial que, segundo Ribeiro (2013), vem transformando os modos de gestão das universidades públicas brasileiras, "[...] há contraditoriamente, garantias legais para que elas exerçam sua autonomia, bem como para que, por meio da gestão colegiada, promovam a participação" (p. 20).

No que diz respeito à participação prevista na estrutura organizacional da UFFS, essa leva em consideração sua característica multicampi. Os Conselhos que compõem a estrutura organizativa de gestão da universidade e suas atribuições seguem descritos no Quadro 1.

Quadro 1 - Os Conselhos Gestores da Universidade Federal da Fronteira Sul (UFFS) e suas atribuições

\begin{tabular}{|l|l|l|}
\hline Conselhos Gestores & \multicolumn{1}{|c|}{ Caráter } & \multicolumn{1}{c|}{ Atribuições } \\
\hline $\begin{array}{l}\text { Conselho } \\
\text { (Coniversitário }\end{array}$ & $\begin{array}{l}\text { Órgão superior de } \\
\text { deliberação }\end{array}$ & $\begin{array}{l}\text { Decisões de caráter institucional, que vão desde as } \\
\text { políticas gerais de ensino, pesquisa e extensão até a } \\
\text { aprovação da prestação de contas da universidade. }\end{array}$ \\
\hline $\begin{array}{l}\text { Conselho de } \\
\text { Campus }\end{array}$ & $\begin{array}{l}\text { Órgão superior de } \\
\text { deliberação e consultivo } \\
\text { no âmbito do campus }\end{array}$ & $\begin{array}{l}\text { Apresenta diversas atribuições, que vão desde } \\
\text { estabelecer regulamentos e definições até propor ao } \\
\text { Conselho Universitário a realização de concursos no } \\
\text { âmbito do campus }\end{array}$ \\
\hline Conselho Curador & $\begin{array}{l}\text { Órgão superior de } \\
\text { controle e fiscalização } \\
\text { da gestão econômico- } \\
\text { financeira }\end{array}$ & $\begin{array}{l}\text { As atribuições vão desde fiscalizar a execução } \\
\text { orçamentária até a solicitação de auditorias sobre a } \\
\text { execução de contratos. }\end{array}$ \\
\hline $\begin{array}{l}\text { Conselho } \\
\text { Estratégico Social }\end{array}$ & $\begin{array}{l}\text { Órgão de caráter } \\
\text { consultivo }\end{array}$ & $\begin{array}{l}\text { Contribuir para a construção da UFFS, comprometendo- } \\
\text { se com a inclusão social e a produção e disseminação } \\
\text { do conhecimento. }\end{array}$ \\
\hline
\end{tabular}

Fonte: UNIVERSIDADE..., 2012g.

Essa estrutura de gestão da UFFS, via Conselhos, inova em relação às outras instituições de Ensino Superior públicas, especialmente pela inclusão do Conselho Estratégico Social, pelo fato de que sua composição prevê a participação de diferentes representações.

Art. 38 Integrarão o Conselho Estratégico Social os seguintes membros: I. 04 (quatro) representantes por estado dos movimentos sociais organizados; II. 02 (dois) representantes das igrejas da região; III. 01 (um) representante das Universidades Comunitárias da Região; IV. 01 (um) representante das Instituições de Educação Superior Públicas da Região; V. 06 (seis) representantes das entidades patronais (Agricultura, Comércio e Indústria), sendo dois da região oeste de Santa Cantarina, dois do noroeste do Rio Grande do Sul e dois do sudoeste do Paraná e seu entorno; VI. 05 (cinco) representantes das associações dos municípios que abrigam os campi da UFFS; VII. 01 (um) representante do Fórum da Mesomercosul; VIII. 02 (dois) professores do ensino fundamental (séries iniciais e séries finais) e um representante dos professores do ensino médio, indicados pelos sindicatos dos professores dos três estados da Região Sul; IX. 03 (três) representantes dos Docentes da UFFS; X. 03 (três) representantes dos Servidores Técnico-administrativos da UFFS; XI. 03 (três) representantes dos Estudantes da UFFS (UNIVERSIDADE..., 2012b, p. 18). 
O Conselho Estratégico Social prioriza, assim, a participação da comunidade externa em sua formação, envolvendo entidades da sociedade local, ligadas a UFFS desde a concepção de seu projeto. Dentre as competências do referido Conselho Estratégico Social, destacam-se:

II. Propor à alta administração da UFFS formas, mecanismos e estratégias para aprofundar a inserção da instituição na comunidade da região; III. Recomendar a execução de ações de natureza política, administrativa e acadêmica que possam melhor colocar a UFFS a serviço do desenvolvimento regional e, em especial, da população mais carente; IV. Propor questões estratégicas, diretrizes gerais, expansão de atividades, criação de novos cursos, em permanente diálogo com a produção acadêmica da instituição, considerando sempre a sua pertinência e seu impacto social para a região da Fronteira Sul; V. Indicar os representantes da comunidade externa no Conselho Universitário, um representante no Conselho Curador, e, nos campi onde não houver Conselho Comunitário, a representação da comunidade externa no Conselho de Campus (UNIVERSIDADE..., 2012b, p. 18, grifos das autoras).

Observa-se, entre as funções desse Conselho, que a ênfase na atuação universitária está voltada ao desenvolvimento regional/territorial, à inclusão da população pobre e à participação da comunidade externa.

Nessa perspectiva de gestão universitária, em que são reforçados processos participativos e decisórios coletivos a serem exercidos por meio de diferentes atores envolvidos, aumentam as possibilidades para desenvolver uma ação dialógica na busca de entendimentos negociados, visando o interesse público (TENÓRIO, 2011). Assim, uma organização, por meio de seus arranjos institucionais, torna-se capaz de promover o que Tenório (2011) concebe como "bem comum republicano",

[...] que implica a busca pela deliberação consensual entre diferentes agentes/atores de dado processo decisório e que, aliado à descentralização, promove o controle social da sociedade em relação ao Estado, democratizando, portanto, as relações sociedade-Estado (p. 76).

Ainda, para esse autor, "práticas gerenciais originadas em processos de descentralização, aliada a processos decisórios colegiados, tem o seu potencial democrático ampliado no nível local e/ou territorial" (p. 76). Nessa lógica de gestão, há que se considerar os Conselhos Gestores como espaços potenciais “[...] à maior organicidade e continuidade da participação social, tanto na definição de prioridades e estratégias para formulação das políticas públicas, quanto no controle e na fiscalização de sua execução" (WENDHAUSEN; KLEBA, 2012, p. 9). Além disso, como espaços de desenvolvimento de relações entre os indivíduos que deles participam e como "[...] fontes de novas práticas e de novos procedimentos", constituem-se em arenas para debates e tomadas de decisão (ABERS; KECK, 2008, p. 101).

Ao considerar que o propósito da existência de fóruns deliberativos - como os Conselhos Gestores - está em reunir atores de diferentes segmentos da sociedade e do governo para exercerem poder de decisão, reconhece-se que "a importância da sociedade civil na vida pública reside em seu papel como arena para a expressão de diversidade" (ABERS; KECK, 2008, p. 106). Tal noção, contudo, tem consequências para o papel da participação desses atores. Desse modo, a efetivação da democratização da gestão pública, por meio da participação social nesses espaços decisórios, ainda é um desafio. 
Almeida Júnior e Tosta (2011, p. 31), ao analisarem os desafios de instalação da UFFS, sua estrutura institucional e a existência de instâncias deliberativas tanto na Reitoria quanto nos campi, afirmam que "existe uma relação dialógica entre as estruturas superiores e as de base na universidade". Alguns sujeitos entrevistados pela presente pesquisa, de forma mais ampla, no entanto, levantam e problematizam algumas questões, como pode ser observado.

Os sujeitos X1 e X2 entendem que algumas decisões devem envolver a comunidade acadêmica e/ou a comunidade externa, tendo em vista sua atribuição precípua, porém outras não; isso pelo fato de que algumas são eminentemente administrativas e devem seguir determinações legais advindas dos órgãos superiores, como é o caso do Ministério da Educação, e outras são pontuais, não precisando ser debatidas com a comunidade acadêmica e/ou externa. De um lado o sujeito X2 ilustra sobre uma decisão envolvendo a comunidade externa: "[...] uma situação que foi bem emblemática foi a proposição de que o conselho estratégico coordenasse o debate sobre a expansão da universidade: De outro, o sujeito X1 pontua: "quando a gente coloca alguém lá, coloca para tomar decisões. [...] têm algumas questões que são muito administrativas, e que parece que fica um pouco sem sentido discutir. Por exemplo, se a gente vai ter telefonia voip ou telefonia comum".

$\mathrm{O}$ comum entendimento dos sujeitos $\mathrm{X} 1$ e X2 expressa uma concepção de gestão que se assemelha com os conceitos da Administração Gerencialista. São procedimentos já regulamentados ou institucionalizados que, para eles, precisam somente ser operacionalizados. Nesse sentido, a Nova Administração Pública afirma que algumas decisões organizacionais precisam ser tomadas de forma muito racional, levando em consideração as "melhores práticas", já testadas e aprovadas pelo setor privado.

Um professor entrevistado com cargo diretivo de gestão, no caso o de reitor, afirma que a UFFS transita entre os diferentes modelos de gestão existentes na administração pública: "eu tenho a impressão que nós estamos [...] caminhando numa estrada intermediária. Nos procedimentos internos a tendência é se aproximar da burocracia, mas naquilo que nós estamos inovando estamos constantemente presentes no regimento societal $[\ldots]$...

De Paula (2003, p. 144) discute que "atualmente, o parâmetro organizacional é a burocracia flexível, que tem características adaptadas às necessidades de flexibilização organizacional, mas não descarta a profissionalização e a dominação burocrática". Dessa forma, embora existam críticas à burocracia, essa mantém sua importância quando da prestação dos serviços públicos, posto que, por meio de procedimentos padronizados, pode assegurar a impessoalidade nos atendimentos aos cidadãos e nas decisões tomadas.

O reitor entrevistado traz exemplos que reforçam alguns obstáculos enfrentados para "manter vivos" os processos participativos numa gestão universitária, como a inserção da comunidade externa. Salienta ele: "à medida que a comunidade acadêmica foi se constituindo, ela foi de alguma forma querendo se isolar das referências externas [...] nós tivemos uma vontade interna assim, de espírito de corporação que poderia colocar em risco esta perspectiva societal". Na sua opinião, isso tem relação com um corpo docente e técnico-administrativo constituído por meio de concurso público, em que as 
pessoas que ingressam na instituição não necessariamente conhecem e estão implicadas com as singularidades históricas voltadas à proposta de gestão participativa e às vocações regionais.

Nesse sentido, ressalta-se a importância de se investir no processo de formação sociopolítica continuada dos servidores públicos que passam a compor o quadro funcional da UFFS, a fim de garantir que o princípio da participação social se fortaleça como mecanismo de gestão, uma vez que seu aperfeiçoamento é um permanente desafio. 0 reitor entrevistado exemplifica sobre uma situação em que a participação de diferentes segmentos, tanto da comunidade interna quanto externa, se coloca fundamental aos processos de uma gestão universitária:

[...] nós continuamos tendo projetos que não poderiam ser realizados sem que voltássemos constantemente num "zig-zag" para concepção societal. Por exemplo, em relação ao curso de Educação do Campo, houve um projeto do Ministério da Educação que nos colocava a necessidade de dialogar com os órgãos comunitários e assim por diante, sobretudo com os movimentos sociais rurais para formação desses projetos.

Relacionado ao que o reitor entrevistado pontua, os sujeitos X1 e X3 destacam que, com o crescimento da UFFS, ocorre certa dificuldade de os segmentos acompanharem todos os processos decisórios, como acontecia no início do seu funcionamento: “[...] há tantos processos que a gente nem está sabendo, porque a universidade, ela já está tão grande, que a gente não consegue mais dar conta. A gente sabe que têm programas de extensão, que são decisões tomadas a partir das demandas sociais colocadas" (SUJEITO X1). Na mesma direção, o sujeito X2 argumenta: "[...] eu acho que a universidade é aberta, nós participamos das decisões, mas não é tudo aquilo que a gente consegue dar. Tu não consegues nem ler, às vezes, a ata que tem 70 páginas; como é que tu vai dar conta?"

Como espaço potencial de participação social, a universidade, neste caso a UFFS, assume um papel propulsor na sua ampliação e qualificação ao criar condições favoráveis para que seus servidores e membros conselheiros possam exercitar a construção da cidadania ativa nas estruturas de participação instituídas internamente. Ao mesmo tempo, assume papel importante para aperfeiçoar o modus operandi de inserção desses sujeitos nos processos de gestão para exercer influência deliberativa e de controle social na gestão universitária.

Tal aperfeiçoamento, contudo, passa a exigir interesse, dedicação representativa e tempo disponível. Não basta "estar ou se fazer mais ou menos presente", uma vez que "participar é fazer parte", é se envolver efetivamente nos processos e nas decisões. Nesse contexto, o intenso movimento de participação social exigido tem se tornado difícil de ser alcançado e mantido, em razão dos obstáculos que se impõem na dinâmica da sociedade contemporânea que afeta a vida pessoal e profissional de indivíduos e grupos.

Jacobi (2003, p. 135) destaca que o principal desafio está em "construir uma ordem societária baseada na articulação da democracia política com a participação social". Nesse sentido, levar a cabo a gestão participativa como estratégia político-administrativa de "governar" em espaços públicos, requer: 
[...] práticas participativas, que apontam, a partir da manifestação do coletivo, para uma nova qualidade de cidadania, que institui o cidadão como criador de direitos para abrir novos espaços de participação sociopolítica, e, de outro, os aspectos que configuram as barreiras que precisam ser superadas para multiplicar iniciativas de gestão que articulam eficazmente a complexidade com a democracia (JACOBI, 2003, p. 315).

O sujeito X3, por sua vez, reforça o argumento do autor, ao lembrar que os movimentos sociais não somente participam por interesse do grupo que representam, mas são "cobrados" pela própria Universidade a participarem das decisões:

Essa universidade inclusive, exige que nós participemos. Então, nós dos movimentos sociais temos uma demanda de trabalho muito grande. [...] nós temos a participação; a universidade é aberta; nós conseguimos dialogar muito bem com a Reitoria da universidade [...] ela é muito próxima da gente, então a gente vai numa reunião da universidade e conversa com eles (SUJEITO X3).

Para o sujeito $\mathrm{X} 2$, outro aspecto relativo à participação se deve ao pouco interesse em fazer parte dos processos de gestão universitária:

Com relação à comunidade acadêmica, eu sinto, às vezes, o pouco interesse em participar. [...] com exceção de algum que outro caso, assim, pontual. A gente viu na última eleição do conselho universitário, por exemplo, alguns espaços de estudantes, que foi deserto em alguns campi. De técnicos, por exemplo, que a gente teve que ir atrás e convencer as pessoas a participarem do processo, para que tivesse representação. Então, isso eu acho que é falta de interesse. E da comunidade externa. [...] a impressão que eu tenho é que havia um objetivo que era conquistar a UFFS; todo mundo se uniu, alcançaram o objetivo e eles mesmos ficaram: E agora? Então, eu acho que tem que haver participação, sendo que participação é diferente de interferência, no meu ponto de vista.

No que diz respeito à participação no espaço público, reconhece-se que, na América Latina e no Brasil, a luta pela conquista de espaços para aumentar a participação social tem sido notável, mas ainda se configura num dos aspectos mais desafiadores da democracia, ao considerar que

[...] as experiências de deliberação participativa, desde o início dos anos 1980, no Brasil, estão associadas à capacidade que os movimentos sociais tiveram de explicitar demandas relacionadas principalmente com a distribuição de bens públicos e também, em menor escala, na formulação de políticas públicas (JACOBI, 2003, p. 135).

De acordo com Gohn (2010), em uma atuação com participação representativa deve prevalecer os interesses da coletividade que os sujeitos representam. Ribeiro (2013) ressalta que os conselhos universitários devem alcançar uma participação "[...] coletiva, ativa e de fato representativa dos interesses da comunidade [...]".

De fato, a cultura de participação nesses órgãos representativos, bem como em comissões para definir procedimentos a serem seguidos e encaminhamentos a serem tomados, precisa ser estimulada e exercitada institucionalmente. Muitas vezes a participação demanda conhecimentos específicos ou, então, disponibilidade de tempo para dedicação a esses trabalhos. Ainda, existem perfis diferentes de pessoas que compõem 
a instituição: algumas delas buscam se envolver de uma maneira mais significativa e efetiva, outras apenas se fazem presentes, e outras tantas se colocam ausentes dos processos de gestão.

A característica multicampi da UFFS é destacada pelo sujeito A1 como um obstáculo à participação mais efetiva da comunidade acadêmica, em razão da distância física entre campus: "[...] eu acho que há, não em todos os processos mas em alguns, uma tentativa de fazer escolhas mais democráticas sim, mas a questão geográfica e de tempo, às vezes, acaba sendo um limitador [...]".O sujeito $A 2$, no entanto, destaca que a participação na gestão da universidade tem ocorrido com certa lentidão nos processos decisórios: "[...] eu considero as reuniões do Conselho Universitário bastante participativas e democráticas. São inclusive lentas por causa disso. [...] é o ônus do processo todo."

Para o sujeito $A 3$, as questões burocráticas estão se sobressaindo pelas decisões que a universidade vem tomando em detrimento da solução dos problemas que são apresentados, colocando-se enfático a respeito:

Acho que ainda há uma incongruência entre as necessidades/anseios da comunidade e burocratização da máquina pública. Muitas coisas deixam de ser feitas ou demoram a serem realizadas por questões de ordem legalista, o que, muitas vezes, frustra as expectativas da sociedade e dos próprios funcionários da instituição. Assim sendo, muitas questões são decididas pelo viés burocrático (o que pode e como deve ser feito) e não pelo viés social (o que se quer, o que é importante para o público assistido). Ou seja, mesmo que se queira e se decida alcançar um fim, sempre se esbarra nos meios.

Percebe-se, pelos relatos dos sujeitos $X 1, X 2$ e A3, que, mesmo orientada pelo fundamento da democracia, a administração pública pode ficar "aprisionada" aos trâmites legais e necessários e a serem cumpridos. A burocracia, para De Paula (2003), pode exercer o controle sobre os seres humanos se aplicada ao pé da letra.

\section{CONSIDERAÇÕES FINAIS}

Desde 1988, com a promulgação da Constituição Federal Brasileira, a participação social na formulação de políticas públicas, o controle da sociedade civil organizada sobre a ação estatal, associados à descentralização, estão estabelecidos como diretrizes organizacionais de gestão em várias áreas setoriais, como é o caso da educação superior.

Reconhece-se que essa potencialidade instituída constitucionalmente tem promovido a participação e a consequente ampliação dos atores sociais envolvidos na gestão da "coisa pública", como é o caso da Universidade Federal da Fronteira Sul.

Não obstante, permanece o desafio de qualificar e, portanto, efetivar os processos participativos e de tomadas de decisão, bem como aperfeiçoar os mecanismos de inserção dos segmentos organizados, a fim de "fazer valer" a representatividade e a legitimidade em meio às estruturas organizacionais de gestão nessa Universidade. 
A Universidade Federal da Fronteira Sul (UFFS), como Instituição pública, imprime, por meio do Conselho Estratégico Social, uma inovação no campo da gestão pública. Esse Conselho pode se constituir numa potência macrorregional para contribuir qualitativa e efetivamente na gestão de uma Universidade comprometida com a participação popular, a inclusão social e com o desenvolvimento local/regional.

Considera-se que "fazer a gestão da UFFS", preservando e assegurando os dispositivos democráticos que a caracterizam - em estreito diálogo com as comunidades interna e externa por meio de seus conselhos gestores -, exige esforços permanentes dos sujeitos envolvidos que, como atores sociais, enfrentam desafios, mas também são capazes de promover uma cultura político-administrativa em seus processos de gestão universitária, fundamentada pela participação e pela democracia.

\section{REFERÊNCIAS}

ABERS, Rebecca Neaera; KECK, Margaret E. Representando a diversidade: Estado, sociedade e relações fecundas nos conselhos gestores. Caderno CRH, Salvador, v. 21, n. 52, p. 99-112, jan./abr. 2008.

ALMEIDA JÚNIOR, Vicente de Paula; TOSTA, Kelli B. T. Universidade pública democrática e popular: os desafios da implantação da Universidade Federal da Fronteira Sul. Gual: Gestão Universitária na América Latina, Florianópolis, Edição Especial, 2011.

BANDEIRA, Pedro. Participação, articulação de atores sociais e desenvolvimento regional. Brasília: Ipea, 1999.

BARBOSA, Renata Trasse de Oliveira. As nuances da reestruturação produtiva na administração pública. SEMINÁRIO DO TRABALHADOR, 8., SEMINÁRIO “O TRABALHADOR EM DEBATE”, 6., UNESP/USP/STICF/ CNTI/UFSC. Franca, SP: Unesp, 2012.

BAVARESCO, Paulo Ricardo. Colonização do extremo oeste catarinense: contribuições para a história campesina da América Latina. Artigo apresentado no Doutorado em Ciências Sociais pela Universidade do Vale do Rio dos Sinos - Unisinos, 2006. Disponível em: <http://www.alasru.org/cdalasru2006>. Acesso: 8 maio 2017.

BENINCÁ, Dirceu (Org.). Universidade e suas fronteiras. Uma universidade em movimento. São Paulo: Outras Expressões, 2011.

BRASIL. Presidência da República. Casa Civil. Subchefia para assuntos jurídicos. Lei 9.394 de 20 de dezembro de 1996. Disponível em: <http://www.planalto.gov.br/ccivil_03/leis//9394.htm>. Acesso em: 24 mar. 2013.

Constituição da República Federativa do Brasil. Presidência da República, 1988. Disponível em: <http://www.planalto.gov.br/ccivil_03/ constituicao/constituicaocompilado.htm>. Acesso em: 24 mar. 2014.

Emenda Constitucional n. 19. Presidência da República, 1998. Disponível em: <http://www.planalto.gov.br/ccivil_03/constituicao/Emendas/Emc/emc19.htm\#art3>. Acesso em: 24 mar. 2014.

Presidência da República. Casa Civil. Subchefia para assuntos jurídicos. Lei 9.192 de 21 de dezembro de 1995. Disponível em: <http://www.planalto.gov.br/ccivil_03/leis/L9192.htm>. Acesso em: 21 mar. 2013.

Presidência da República. Casa Civil. Subchefia para assuntos jurídicos. Decreto no 6.096 de 24 de Abril de 2007. Disponível em: <http://www.planalto.gov.br/ccivil_03/_Ato2007-2010/2007/Decreto/ D6096.htm>. Acesso em: 21 jul. 2013.

Presidência da República. Decreto 1.196 de 2 de setembro de 1996. Disponível em: <http://www. planalto.gov.br/ccivil_03/decreto/1996/D1996.htm>. Acesso em: 3 fev. 2014.

Ministério da Integração Nacional. Política Nacional de Desenvolvimento Regional. Disponível em: <http://www.integracao.gov.br/politica-nacional-de-desenvolvimento-regional-pndr>. Acesso em: 21 jun. 2013.

BRESSER-PEREIRA, Luiz Carlos. Reforma do Estado para a cidadania: reforma gerencial brasileira na perspectiva internacional. São Paulo: 34; Brasília: Enap, 1998.

BRESSER-PEREIRA, Luiz Carlos; SPINK, Peter Kevin (Org.). Reforma do Estado e Administração Pública Gerencial. Rio de Janeiro: FGV, 2006.

jan./abr. 1996. 
CARVALHO, Roberto Francisco de. Limites, possibilidades e desafios no processo de gestão e participação da IFES/UFT. Avaliação, Campinas, v. 18, n. 2, p. 351-372, 2013.

CHAVES, Débora Almeida; DA SILVA, Marcos Raimundo Pereira. Administração pública gerencial: dificuldades de implementação nas organizações públicas. CONGRESSO SUL BRASILEIRO DE ADMINISTRAÇÃO PÚBLICA, Curitiba, 2010.

CHIAVENATTO, Idalberto. Introdução à teoria geral da administração: uma visão abrangente da moderna administração das organizações. 7. ed. Rio de Janeiro: Elsevier, 2003.

COLETTI, Tomé. Agroindústria suinícola e agricultura familiar: uma "crônica" sobre a trajetória histórica do oeste catarinense. Florianópolis: UFSC, 2009.

COSTA, Frederico Lustosa da. Brasil: 200 anos de Estado; 200 anos de administração pública; 200 anos de reformas. Rev. Adm. Pública (RAP), v. 42, n. 5, p. 829-874, 2008.

DAMO, Marcia Regina Sartori. Análise da descentralização administrativa do governo do Estado e os efeitos da fragmentação territorial no oeste catarinense. Florianópolis: UFSC, 2006.

DE PAULA, Ana Paula Paes. Entre a administração e a política: os desafios da gestão pública democrática. 2003. Tese (Doutorado) - Universidade Estadual de Campinas, Campinas, SP, 2003.

Administração pública brasileira entre o gerencialismo e a gestão social. Revista de Administração de Empresas, v. 45, n. 1, jan./mar. 2005.

DORIGON, Clóvis; RENK, Arlene. Técnicas e métodos tradicionais de processamento de produtos coloniais: de "miudezas de colonos pobres" aos mercados de qualidade diferenciada. CONGRESSO ALASRU, 8., 2010. Pernambuco. Registrado no CCTC, Rea-2/2011.

ÉSTHER, Angelo Brigato. As competências gerenciais dos reitores de universidades federais em Minas Gerais: uma visão da alta administração. Cadernos EBAPE.BR, Rio de Janeiro, v. 9. Edição Especial, artigo 10, 2011.

FÓRUM DE DESENVOLVIMENTO DA MESORREGIÃO DA FRONTEIRA SUL. Estatuto, 2002.

GODOY, A. S. Introdução à pesquisa qualitativa e suas possibilidades. Revista de Administração de Empresas, São Paulo, vol. 35, n. 2, mar./abr. 1995.

GOHN, Maria da Glória. Conselhos gestores e participação sociopolítica. 4. ed. São Paulo: Cortez, 2010.

JACOBI, Pedro Roberto. Espaços públicos e práticas participativas na gestão do meio ambiente no Brasil. Sociedade e Estado, Brasília, vol. 18, n. 1-2, p. 315-338, dez. 2003. Disponível em: <http://www.scielo.br/ scielo.php?pid=S0102-6992200300010001script=sci_arttext>. Acesso em: 10 jul. 2016.

MARTINS, José de Souza. Os camponeses e a política no Brasil: as lutas sociais no campo e seu lugar no processo político. 5. ed. Petrópolis: Vozes, 1995.

MINAYO, Maria Cecília de Souza. O desafio do conhecimento: pesquisa qualitativa em saúde. São Paulo: Hucitec, 2008.

MINISTÉRIO DA ADMINISTRAÇÃO E REFORMA DO ESTADO (Mare). Plano Diretor da Reforma do Estado. Brasília: Mare, 1995.

MINISTÉRIO DA INTEGRAÇÃO NACIONAL. Política Nacional de Desenvolvimento Regional. Disponível em: <http://www.integracao.gov.br/politica-nacional-de-desenvolvimento-regional-pndr>. Acesso em: 10 jun. 2013.

POLI, Odilon. Leituras em movimentos sociais. 2. ed. Chapecó: Argos, 2008.

PRADO, Maurício Almeida. O modelo gerencial da educação: contribuições da experiência da Inglaterra ao debate brasileiro. Revista do Serviço Público, Brasília, jul./set. 2011.

RENK, Arlene. A luta da erva: Um ofício étnico da nação brasileira no Oeste Catarinense. 2 ed. rev. Chapecó: Argos, 2006.

RIBEIRO, Maria Edilene da Silva. A gestão universitária: um estudo na UFPA de 2001 a 2011. 2013. 290f. Tese (Doutorado) - Universidade Federal do Pará, Instituto de Ciências da Educação, Programa de Pós-Graduação em Educação, Belém, 2013.

ROVER, Oscar José. Redes de poder e governança local: análise da gestão político-administrativa em três fóruns de desenvolvimento com atuação na região Oeste de Santa Catarina. Porto Alegre: UFRGS, 2007.

SANTOS, José Vicente Tavares dos. Colonos do vinho: estudo sobre a subordinação do trabalho camponês ao capital. São Paulo: Hucitec, 1978.

SCHERER-WARREN, Ilse. Das mobilizações às redes de movimentos sociais. Sociedade e Estado, v. 21, n. 1, p. 109-130, jan./abr. 2006.

Redes emancipatórias: nas lutas contra a exclusão e por direitos humanos. Curitiba: Appris, 2012.

SECCHI, Leonardo. Modelos organizacionais e reformas da administração pública. Revista de Administração Pública, Rio de Janeiro, v. 43, n. 2, mar./abr. 2009. 
SEVERINO, Antônio Joaquim. Metodologia do trabalho científico. 23. ed. São Paulo: Cortez, 2007.

SILVA, C. E. S. Autonomia de gestão e concorrência: em busca de novas formas de gestão do setor público em um contexto pós-fordista. Revista de Administração Pública, Rio de Janeiro, p. 211-228, out./dez. 1994. TENÓRIO, Fernando G. Gestão social: uma perspectiva conceitual. Revista de Administração Pública, Rio de Janeiro, v. 32, n. 5, p.7-23, set./out. 1998.

Cidadania e desenvolvimento local: casos brasileiros. CONGRESO INTERNACIONAL DEL CLAD SOBRE LA REFORMA DEL ESTADO Y DE LA ADMINISTRACIÓN PÚBLICA, 9., 2004. Madrid, España, 2-5 nov. 2004.

Descentralização político-administrativa, gestão social e participação cidadã. In: DALLABRIDA, Valdir Roque (Org.). Governança territorial e desenvolvimento: descentralização político-administrativa, estruturas subnacionais de gestão do desenvolvimento e capacidades estatais. Rio de Janeiro: Garamond, 2011.

TESTA, V. M. et al. O desenvolvimento sustentável do oeste catarinense (proposta para discussão). Florianópolis: Epagri, 1996. 247p.

TREVISOL, Joviles; CORDEIRO, Maria Helena; HASS, Mônica (Org.). Construindo agenda e definindo rumos. CONFERÊNCIA DE ENSINO, PESQUISA E EXTENSÃO DA UFFS, 1., 2011. Chapecó: UFFS, 2011.

TRIVIÑOS, A. N. S. Introdução à pesquisa em ciências sociais: a pesquisa qualitativa em educação. São Paulo: Atlas, 1987.

UNIVERSIDADE FEDERAL DA FRONTEIRA SUL (UFFS). Edital № 162/UFFS/2011: Processo seletivo UFFS 2012. Disponível em: Acesso em: 2 fev. 2014.

Plano de Desenvolvimento Institucional - PDI. 2012a. Disponível em: <http://www.uffs.edu.br/ index.php?option=com_content\&view=article\&id=2630\&Itemid=1502\&site=proplan>. Acesso em: 2 fev. 2014.

Estatuto. 2012b. Disponível em: <http://www.uffs.edu.br>. Acesso em: 3 fev. 2014.

Ata da 2a Reunião Ordinária da Câmara de Graduação. 2013a. Disponível em: <http://www.uffs.

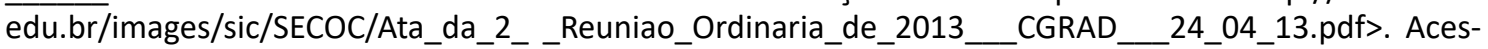
so em: 19 jan. 2014.

. Ata da 4a Reunião Ordinária de 2013 da Câmara de Graduação. 2013b. Disponível em: <http:// www.uffs.edu.br/images/sic/SECOC/Ata_da_4_Reuniao_Ordinaria_de_2013__CGRAD__24_06_13. pdf>. Acesso em: 19 jan. 2014.

. Resolução n. 6/2013 - CONSUNI/CGRAD. 2013c. Disponível em: <http://www.uffs.edu.br/images/SECOC/006-2013_-_CONSUNI-CGRAD_-_aprova_as_normas_protocolares_para_solenidade_de_colao_de_grau.pdf $>$. Acesso em: 19 jan. 2014.

Ata da $5 \underline{a}$ sessão do Conselho Universitário. 2013d. Disponível em: <http://www.uffs.edu.br/in$\overline{\text { dex.php}}$ ?option=com_content\&view=category\&layout=blog\&id=261\&ltemid=1913\&site=consuni $>$. Acesso em: 6 abr. 2014.

Ata da $7 \underline{a}$ sessão do Conselho Universitário. 2013e. Disponível em: <http://www.uffs.edu.br/in$\overline{\text { dex.php}}$ ?option=com_content\&view=category\&layout=blog\&id=261\&ltemid=1913\&site=consuni $>$. Acesso em: 6 abr. 2014.

A instituição. 2013f. Disponível em: <http://www.uffs.edu.br/index.php?option=com_content\&view=article\&id=90\&Itemid=822>. Acesso em: 12 fev. 2013.

WEBER, Max. Economia e sociedade: fundamentos da sociologia compreensiva. Brasília, DF: Ed. Universidade de Brasília, 1999. Press, 1947.

Theory of social and economic organization. Trad. Talcott Parsons. Nova York: Oxford University

WENDHAUSEN, Águeda Lenita Pereira; KLEBA, Maria Elisabeth (Org.). Conselhos Gestores e empoderamento: vivências e potenciais da participação social na gestão pública. Jundiaí: Paco Editorial, 2012. 